\title{
A field comparison of two capture-mark-recapture estimators of small mammal populations
}

\author{
Rosana Gentile ${ }^{1,2}$ \\ Fernando A.S. Fernandez ${ }^{1}$
}

\begin{abstract}
The results obtained by two estimators of population sizes, MNKA and $\mathrm{Mh}$, were compared for four species of small mammmals - Didelphis aurita Wied, 1826, Philander frenata (Olfers, 1818), Nectomys squamipes (Brants, 1827) and Akodon cursor (Winge, 1887) - during a long-term population study. The MNKA estimator consistently underestimated the population sizes in relation to $\mathrm{Mh}$. On the other, the probabilistic estimator $\mathrm{Mh}$, which reduces bias through the jackknife technique, could not be used in all cases as its assumptions were not always met. Correction factors between the estimates obtained by the two methods were calculated for the last three species, for which catchability did not vary significantly in time and that presented positive correlation between the estimates by the two models. In order to combine the adavantages of both methods for small mammal population studies, is suggested the use of probabilistic closed population models and to calculate a correction factor based in another model which allow estimates in all cases, and which provides correlated estimates. This correction factors should be used in those cases where the probabilistic model cannot be used.

KEY WORDS. Capture-recapture, jackknife estimator, minimun number known alive, population size
\end{abstract}

Capture-mark-recapture population estimation models have been widely described in the literature. For closed populations, several models have been developed which do not make the restrictive assumption of equal catchability; this asssumption is a problem when estimating population size of animals of complex behaviour such as mammals. There are models which deal with heterogeneity of capture probabilities among individuals (BURNHAM \& OVERTON 1979; CHAO 1988), along time (DARROCH 1958), or due to behavioural response to traps (OTIS et al. 1978); the first and third problems can also be dealt with altogether (Model Mbh, OTIS et al. 1978). However, no model has been proposed which allows to deal with the three sources of heterogeneity simultaneously; the source(s) not dealt with remain as assumptions to be fulfilled (SEBER 1986).

The main difficulty in the application of such probabilistic models is to collect enough data to satisfy all the assumptions. Data collected with emphasis in

1) Departamento de Ecologia, Instituto de Biologia, Universidade Federal do Rio de Janeiro. Caixa Postal 68020, 21941-590 Rio de Janeiro, Brasil.

E-mail: rosana@rio.com.br.

2) Programa de Pós-Graduação em Genética, Departamento de Genética, Universidade Federal do Rio de Janeiro. 21941-590 Rio de Janeiro, Rio de Janeiro, Brasil. 
quantity often violate the assumptions, on the other hand, data collected in order to satisfy all assumptions can be scarce. The attempt to get rid of restrictive assumptions seems to be the reason why simple deterministic estimators like enumeration - number of different individuals captured - and Minimum Number Known Alive (KREBS 1966) are still widely used in mammalian studies (MONTGOMERY 1987; FERNANDEZ 1995). However, these methods also present their own restrictive assumptions, that are frequently ignored, and which can make them unsuitable even for comparative purposes (HILBORN et al. 1976).

This paper intends to compare population size estimates of two models, one deterministic and one probabilistic for closed populations. We aim to investigate the occurrence of correlations between the estimators of each model; to establish a correction factor between estimators which are correlated; and to propose a procedure for the application of a population estimation procedure for long-term studies using mark-recapture method. The comparisons are all based on field data, obtained during a four-year population study on four species of small mammals.

\section{MATERIAL AND METHODS}

A capture-mark-recapture study of small mammals was carried out in a rural area at Sumidouro, State of Rio de Janeiro, Brazil, every other month, from June 1991 to May 1995 . The study area was in the Pamparrão valley $\left(22^{\circ} 02^{\prime} 46^{\prime \prime S}\right.$, $42^{\circ} 41^{\prime} 21^{\prime \prime W}$ ), characterized by small rural properties with vegetable plantations, pasturelands and small fragments of the Atlantic forest. Captures were carried out in wire-mesh live-traps $(32 \times 18 \times 20 \mathrm{~cm})$, spaced $13 \mathrm{~m}$ apart, and baited with peanut butter, rolled oat, banana and bacon on manioc slices. They were distributed in seven line transects spread along the valley during five nights per trapping period, amounting to a total of 9478 trap-nights. All transects were placed along steams except one, which was placed on a forest fragment - see GENTILE \& FERNANDEZ (1999) for a more detailed description of the study area.

Species analysed were the common opossum Didelphis aurita Wied, 1826, the gray four-eyed opossum, Philander frenata (Olfers, 1818), the water rat Nectomys squamipes (Brants, 1827), and the field rat Akodon cursor (Winge, 1887). Marsupials were marked by tail tatooing and rodents and pouch young by toe-clipping. Thirty individuals were removed for species identifications nearly one year before the start of the mark-recapture study. Identifications were based on morphology and/or karyotipe and were done by Laboratório de Vertebrados at Universidade Federal do Rio de Janeiro. These individuals were deposited as voucher specimens at Museu Nacional do Rio de Janeiro.

Population sizes were estimated through the Mh (Heterogeneity model) of BURNHAM \& OVERTON (1979) - a probabilistic closed population model which allows heterogeneity of captures among individuals - and through The Minimum Number Known Alive (KREBS 1966) - a deterministic model for closed populations.

The assumptions of the Mh model were tested according to BURNHAM \& OVERTON (1979) tests of equal probability of capture in time and population closure. The estimator was calculated only when both assumptions were met. 
Trapability estimates were calculated per trapping period for each species, dividing the number of captures of each individual by the number of trapping days from its first to its last capture. An ANOVA (ZAR 1996) was performed to test if trapability varied through time. Population size estimates of each model were correlated pairwise using Concordance Correlation, $\rho_{\mathrm{c}}$, which is especially suited to compare different measures of the same variable (LIN 1989; ZAR 1996). Neither Lin or Zar provide ways of assessing the significance of $\rho_{c}$, the agreement of the measures being evaluated by the magnitude of the coefficient. As this method assumes data normaly distributed, the values of the estimates were transformed using natural logarithms before calculating the correlations. For species where a positive correlation was found, and trapability did not vary significantly along time, a correction factor was established dividing the estimates of each model by the estimate by the other model, and calculating the average across months. The factors were calculated using only the estimates of months in which both models of each pair could be estimated. All comparisons were carried for each species separately.

\section{RESULTS}

During 24 trapping periods 108 individuals of $D$. aurita were captured with a mean of 8.5 individuals with standard deviation of the sample of 4.1 individuals per period and coefficient of variation of $48.2 \%, 62$ individuals of $P$. frenata $(4.3 \pm$ $2.5, \mathrm{cv}=58.1 \%), 121$ individuals of $N$. squamipes $(10.2 \pm 6.6, \mathrm{cv}=64.7 \%)$ and 120 individuals of $A$. cursor $(7.8 \pm 6.5, \mathrm{cv}=83.3 \%)$.

Population size estimates through each model for $D$. aurita, $P$. frenata, $N$. squamipes and A. cursor are in table I. The MNKA model frequently underestimates population size in relation to the others.

The assumption of population closure of the Mh model was not met in seven cases in D. aurita, three cases in P. frenata, five in $N$. squamipes and three in $A$. cursor. The assumption of equal probability of capture in time failed in only one case in $N$. squamipes.

Trapability estimates varied along time only in $D$. aurita $(\mathrm{F}=2.112, \mathrm{df}=$ $23,141 ; \mathrm{P}=0.004)$. For the other species there is no evidence of such variation $(P$. frenata: $\mathrm{F}=0.574, \mathrm{df}=21,46 ; \mathrm{P}=0.915 ; N$. squamipes: $\mathrm{F}=0.722, \mathrm{df}=22,145 ; \mathrm{P}$ $=0.812 ;$ A. cursor: $\mathrm{F}=1.388, \mathrm{df}=22,166 ; \mathrm{P}=0.127$ ).

Results of the Concordance Correlation coefficients showed that the two methods generated highly consistent estimates for $P$. frenata $\left(\rho_{\mathrm{c}}=0.920, \mathrm{~N}=11\right)$ and for $N$. squamipes $\left(\rho_{\mathrm{c}}=0.898, \mathrm{~N}=14\right)$, but not for $A$. cursor $\left(\rho_{\mathrm{c}}=0.475, \mathrm{~N}=\right.$ 10). Thus, was calculated correction factors for the two former species only: $P$. frenata: $\mathrm{Mh}=1.20 \mathrm{MNKA}, N$. squamipes: $\mathrm{Mh}=1.24 \mathrm{MNKA}$.

\section{DISCUSSION}

MNKA can produce biased estimates because the method is quite sensitive to the low capturability of unmarked individuals (HILBORN et al. 1976; EFFORD 1992; BOULANGER \& KREBS 1994). Mh tends to produce less biased estimates, as it does not make the unrealistic assumption of equal probability of capture among animals (BURNHAM \& OVERTON 1979). 
Table I. Population size estimates through Mh model (estimates and their standard errors) and through MNKA, for four small mammal species in Sumidouro, Rio de Janeiro, Brazil. (-) Insufficient data to apply the model, absence of captures or assuptions not met.

\begin{tabular}{|c|c|c|c|c|c|c|c|c|c|c|c|c|}
\hline & \multicolumn{3}{|c|}{ Didelphis aurita } & \multicolumn{3}{|c|}{ Philander frenata } & \multicolumn{3}{|c|}{ Nectomys squamipes } & \multicolumn{3}{|c|}{ Akodon cursor } \\
\hline & $\mathrm{Mh}$ & SE & MNKA & $\mathrm{Mh}$ & SE & MNKA & $\mathrm{Mh}$ & SE & MNKA & $\mathrm{Mh}$ & SE & MNKA \\
\hline June 91 & 7.8 & 2.35 & 7 & - & - & 2 & 3.80 & 2.35 & 3 & - & - & 0 \\
\hline August 91 & 8.8 & 2.35 & 8 & - & - & 2 & - & - & 0 & 36.6 & 16.6 & 15 \\
\hline October 91 & 6.8 & 2.35 & 6 & - & - & 1 & 5.60 & 3.33 & 4 & 28.8 & 8.71 & 19 \\
\hline January 92 & 18.2 & 9.71 & 9 & - & - & 0 & - & - & 1 & 16.0 & 5.26 & 14 \\
\hline March 92 & 8.6 & 3.33 & 8 & 2.80 & 2.35 & 2 & 8.40 & 4.07 & 6 & - & - & 12 \\
\hline May 92 & 13.4 & 4.07 & 11 & 2.00 & 0.00 & 2 & 13.20 & 4.70 & 10 & 17.7 & 6.13 & 16 \\
\hline July 92 & - & - & 7 & - & - & 2 & - & - & 7 & - & - & 13 \\
\hline October 92 & - & - & 3 & 2.00 & 0.00 & 2 & 9.40 & 4.07 & 8 & 18.4 & 6.65 & 16 \\
\hline December 92 & - & - & 2 & - & - & 1 & 12.20 & 4.70 & 11 & 26.5 & 13.6 & 13 \\
\hline January 93 & - & - & 5 & - & - & 2 & 23.68 & 6.41 & 18 & 8.4 & 4.07 & 8 \\
\hline March 93 & 14.8 & 5.76 & 11 & 5.60 & 3.33 & 5 & - & - & 21 & - & - & 2 \\
\hline May 93 & - & - & 8 & 6.60 & 3.33 & 6 & 16.20 & 4.70 & 18 & 9.2 & 4.70 & 6 \\
\hline July 93 & 11.6 & 3.33 & 11 & - & - & 10 & - & - & 11 & - & - & 9 \\
\hline September 93 & 7.6 & 3.33 & 6 & 8.60 & 3.33 & 7 & 6.80 & 2.35 & 8 & 19.7 & 12.10 & 8 \\
\hline November 93 & 4.8 & 2.35 & 4 & 10.20 & 4.70 & 7 & - & - & 5 & 13.8 & 5.76 & 7 \\
\hline January 94 & 4.0 & 0.00 & 6 & - & - & 2 & - & - & 0 & - & - & 1 \\
\hline March 94 & 8.4 & 4.07 & 7 & - & - & 2 & - & - & 3 & - & - & 4 \\
\hline May 94 & - & - & 9 & 3.80 & 2.35 & 3 & - & - & 3 & - & - & 3 \\
\hline July 94 & 10.4 & 4.07 & 8 & 2.80 & 2.35 & 2 & 3.80 & 2.35 & 3 & - & - & 2. \\
\hline September 94 & - & - & 3 & - & - & 1 & - & - & 2 & - & - & 2 \\
\hline November 94 & 5.6 & 3.33 & 4 & - & - & 1 & 4.80 & 2.35 & 4 & - & - & 2 \\
\hline January 95 & 5.6 & 3.33 & 6 & - & - & 0 & 11.20 & 4.70 & 7 & - & - & 4 \\
\hline March 95 & - & - & 10 & 2.97 & 1.93 & 3 & 6.60 & 3.33 & 5 & - & - & 4 \\
\hline May 95 & 9.6 & 3.33 & 8 & 4.80 & 2.35 & 4 & 9.60 & 3.33 & 8 & - & - & 4 \\
\hline
\end{tabular}

The results of the equal capturability assumption test of Mh model indicated that the capture history of individuals within each trapping period did not influence their capture probabilities, since the test failed in only one case. However, the test of assumption of population closure failed in 18 cases. This can be due to the transect sampling design. The lack of correlation between the estimators for A. cursor probably happens because MNKA underestimated its population more than it did for the other species (Tab. I). This pattern is to be expected as this species showed quick population turnover and low recapture rates, implying in a lower catchability.

Probabilistic models for closed populations generally provide better estimates of population size when compared to deterministic models, because they have less assumptions, and therefore, tend to be less biased. Nevertheless, complex closed population models require more data, and in many cases cannot be used, as occurred in this study.

In view of these problems, is suggested a new procedure to estimate population size for capture-mark-recapture long-term studies: a) To estimate population size using a probabilistic model for closed populations, which assumptions are met in most cases; b) to estimate population size using a simpler model (like MNKA), which allows estimation in all cases; c) to examine the variation of trapability along time; d) if trapability does not vary significantly, to test if there is a positive correlation between the estimates obtained by the two methods; e) if there is positive correlation, calculate a correction factor between the models, as described above. If 
there is no correlation, the factor cannot be calculated and the model to be used must be chosen according to the objectives of the study and to the quantity of data; f) to estimate all cases that cannot be obtained by the probabilistic closed population model using the correction factor; g) to estimate survivorship and recruitment rates through a probabilistic open population model, according to the robust design proposed by POLLOCK (1982).

This procedure could allow using the advantages of little biased probabilistic methods such as $\mathrm{Mh}$, in cases where the data are not consistently abundant throughout the study.

ACKOWLEDGEMENTS. We would like to thank C.E.V. Grelle and C. Horta for the help in the field work, P.S. D'Andrea for providing support and help for the field work and comments during the whole study, L. Rey and R. Cerqueira for the existence of the project, and H.G. Bergallo for comments. We also thank Conselho Nacional de Desenvolvimento Científico e Tecnológico (CNPq), Fundação de Amparo à Pesquisa do Rio de Janeiro (FAPERJ), Instituto Oswaldo Cruz (FIOCRUZ), and Fundação José Bonifácio (FUJB) for financial support.

\section{REFERENCES}

Boulanger, J. \& C.J. KReBS. 1994. Comparison of capture-recapture estimators of snowshoe hare populations. Can. Jour. Zool. 72: 1800-1807.

Burnham, K.P. \& W.S. Overton. 1979. Robust estimation of population size when capture probabilities vary among animals. Ecology 60 (5): 927-936.

CHAO, A. 1988. Estimating animal abundance with capture frequency data. Jour. Wildl. Manage. 52: 295-300.

DARROCH, J.N. 1958. The multiple-recapture census: I. Estimation of a closed population. Biometrika 45: 343-359.

EFFORD, M. 1992. Comment - revised estimates of the bias in the minimum number alive estimator. Can. Jour. Zool. 70: 628-631.

FERNANDEZ, F.A.S. 1995. Métodos para estimativas de parâmetros populacionais por captura, marcação e recaptura. Oecologia brasiliensis 2: 1-26.

GENTILE, R. \& F.A.S. Fernandez. 1999. Influence of habitat structure on a streamside small mammal community in a Brazilian rural area. Mammalia 63 (1): 29-40.

HilBORN, R.; J.A. REDFIELD \& C.J. KREBS. 1976. On the reliability of enumeration for mark recapture census of voles. Can. Jour. Zool. 54: 1019-1024.

KREBS, C.J. 1966. Demographic changes in fluctuating populations of Microtus californicus. Ecol. Monogr. 36: 239-273.

LIN, L.I.K. 1989. A concordance correlation coefficient to evaluate reproducibility. Biometrics 45: 255-268.

MonTGOMERY, W.I. 1987. The application of capture-mark-recapture methods to the enumeration of small mammal populations. Symp. Zool. Soc. Lond. 58: 25-57.

Otis, D.L.; K.P. Burnham; G.C. White \& D.R. Dusel. 1978. Statistical inference from capture data on closed animal populations. Wildl. Monogr. 62: 1-135. 
POLLOCK, K.H. 1982. A capture-recapture design robust to unequal probablity of capture. Jour. Wildl. Manage. 46 (3): 752-757.

SEBER, G.A.F. 1986. A review of estimating animal abundance. Biometrics 42: 267-292.

ZAR, J.H. 1996. Biostatistical Analysis. New Jersey, Prentice Hall, X+662p.

Recebido em 06.VIII.1998; aceito em 07.X.1999. 